WellBeing International

WBI Studies Repository

$12-1985$

\title{
Winning With Archimedian Principles
}

Henry Spira

Coalition to Abolish the LD50 and Draize Tests

Follow this and additional works at: https://www.wellbeingintlstudiesrepository.org/hensart

Part of the Animal Studies Commons, Civic and Community Engagement Commons, and the Politics and Social Change Commons

\section{Recommended Citation}

Spira, H. (1985). Winning with Archimedian principles. ATLA: Alternatives to Laboratory Animals, 13(2), 117-122.

This material is brought to you for free and open access by WellBeing International. It has been accepted for inclusion by an authorized administrator of the WBI Studies Repository. For more information, please contact wbisr-info@wellbeingintl.org.

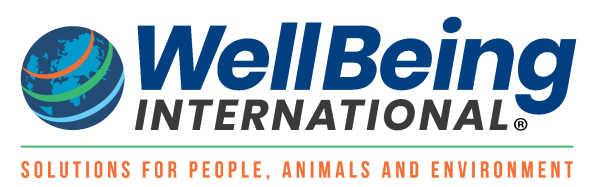




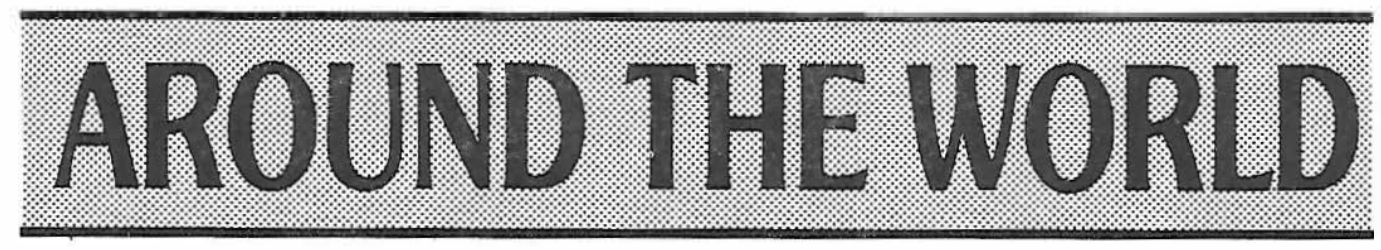

\title{
Winning With Archimedian Principles
}

\author{
Henry Spira \\ Coalition to Abolish the LD50 and Draize Tests, 1 West 85th Street, \\ New York, NY 10024, USA
}

The history of the animal welfare movement has generally been marked by failure, leading to feelings of hopelessness and frustration within the movement. The difficulty of shifting scientific research away from the present massive reliance on animals, as well as the inertia caused by entrenched social attitudes towards animals, together make it appear that change is impossible. The question is, how to move what appears to be a monolith, consisting of an obdurate social "reality" and seemingly unchangeable scientific necessities. We feel that we have made significant steps in moving that monolith and that our successes have resulted from specific strategies, which developed as we went along.

I use "we" rather than "I" throughout this paper to indicate that both the actions and the ideas described are the product of a loose organisation of many concerned individuals, an interaction of energies for which the Coalition to Abolish the Draize and LD50 Tests is the current crystalisation.

We describe the strategies used, not only for intrinsic interest, but also because we feel they can be usefully applied to other areas. We call these strategies "Archimedian", in the sense that we use actions as fulcrums and levers to move progressively larger problemweights.

Our strategies are patterned to some extent on the progressively greater successes of the human rights movement in this century, but also address the specific mesh of technical and social difficulties and opportunities that we encounter in the animal rights debate. A large part of the credit for our successes belongs to approaches (long anticipated by FRAME and UFAW) that are not "all or none", but that are patterned on incremental activities and actively seek to engage members of the scientific community as collaborators. As one aspect of this approach, we choose directions of change in which, so far as is possible, everybody wins, and which can be considered as logically inevitable. It is then possible to transform the former "opponent" into an ally. Thus, each success can be the base for the next effort. The scientific benefits to be obtained by replacing or reducing the use of animals are emphasised, where possible.

We have avoided bureaucratisation by keeping the organisation down to an absolute minimum-a loose network of persons of varying expertise, meeting informally to discuss goals as they arise or are created. Thus, this article is the result of close collaboration with Leonard Rack MD. Dr Rack was the first member of our science advisory group, composed of highly skilled professionals, among them Dr Andrew Rowan, author of "Mice, Models and Men" (1), who, like Dr Rack, is deeply interested in alternatives to animal testing. 
The Coalition's "think tank" researches and analyses, finds patterns and connections, seeks vulnerable points that offer maximum leverage and then produces facts sheets and reports, and organises public demonstrations and boycotts. Our current campaigns involve more than 400 organisations with combined memberships in the millions, banded together to abolish the Draize and LD50 tests.

Our Coalition can assemble different elements to maximise pressure by approaching the issue from every direction on every level, whilst remaining an orchestrated, purposeful action. Participation in the Coalition is encouraged at whatever level organisations and individuals feel are appropriate for them. For example, Pegeen Fitzgerald, President of the Millennium Guild, has paid all of the Coalition's out-of-pocket expenses, ranging from telephone bills to travel, in addition to placing full-page advertisements in major newspapers, thereby creating turning points in several campaigns. Robert Ford, President of the New England Antivivisection Society (NEAVS), has also placed anti-Draize and LD50 test advertisements. Both NEAVS and the Millennium Guild have provided substantial funding to promote alternatives through publications and grants. Other organisations have produced massive mailings and have contacted legislators.

As noted previously, our strategy has been an incremental one-step-by-step approach that uses each victory as a stepping stone to more significant struggles. This approach has promoted rapid social change, as we moved from 60 cats in our American Museum of Natural History protest, to hundreds of thousands of rabbits in the Draize campaign, and then to the millions of animals used in the classic LD50 test.

\section{At the American Museum of Natural History}

Peter Singer's essay, "Animal Liberation" (2), inspired me to turn the political experience of several decades in the direction of animal rights. I formed an ad hoc group to find a worthy adversary and a vulnerable point for our first campaign. At that time, researchers at New York's American Museum of Natural History were mutilating cats to learn about human sexuality, a project which caused much pain and was scientifically irrelevant.

Our preparations began with a request, under the US Federal Freedom of Information Act, for all project proposals, progress reports, and other papers. We asked that the fees be waived on the grounds that this was in the public interest. As a result, the total cost of this investigation was 62 cents. Armed with this documentation, we tried to talk with Museum officials, but they refused to talk to us. We then circulated the Museum documents which outlined how the experimenters planned to deafen, blind and destroy the sense of smell of cats by removing parts of their brains. We wrote a detailed exposé for Our Town (3), a Manhattan weekly newspaper; then we set up pickets outside the Museum. Every weekend, for 18 months, we maintained pickets or demonstrations outside the Museum.

At first the Museum refused to budge, but the pressure grew to the point where 121 members of Congress had questioned the National Institutes of Health (NIH) over its funding of the experiments. A long, and surprisingly favourable, report on our campaign appeared in Science in 1976 (4). It seemed that at least some members of the scientific community wished to dissociate themselves from such experiments.

The Museum was vulnerable. The demonstrations hurt its image, and the cancellations of members' subscriptions that began pouring in were threatening to damage its budget. Finally the NIH stopped funding the experiments, and the laboratories where the work had been done were dismantled.

\section{From the Shelter to the Laboratory}

Our next target was a New York State law known as the Metcalf-Hatch Act. This law allowed researchers to seize stray dogs and cats from the very pounds ostensibly built to save them from the misery of the streets. For 27 years, New York animal welfare groups had been trying in vain to get this law repealed. We felt that it was a betrayal of the public which had worked to create the animal shelters. Both the law itself and the failure to get the law 
repealed, were symbols of the powerlessness and political ineffectiveness of the animal welfare movement. So we organised a coalition and started lobbying the state legislators.

We soon discovered that no-one had previously tried to talk to the legislator who had been the chief stumbling block in the way of repeal, Senator Lombardi. As Chairman of the relevant committee, he had prevented the issue from even being debated. The animal welfare groups had accused him of being in the pay of the pharmaceutical industry and had taken the attitude that there was no point in talking to him. We went the other way; we went to him and indicated that we were not seeking a fight, but that we wanted to get the issue debated on its merits, and voted on. We suggested that whatever his beliefs about the issue might be, we had the democratic right to have the issue debated. Because we had approached him without animosity, we were able to build up a positive relationship with him. He maintained his opinion that the pound seizure law should not be repealed, but he allowed the issue to be debated-which was crucial. When the debate was over, the issue was voted on, and we won. We then put out a press release thanking Senator Lombardi for giving us a fair hearing. This was important. It showed that we were not out to attack or victimise anyone, but only wanted to improve the situation for animals.

This was our second victory, and again an important one for our morale; but it was still largely symbolic, involving maybe a few thousand animals. Now it was time to move on to something much more significant.

\section{The Draize Rabbit Eye Test}

The Draize eye test routinely uses the eyes of unanaesthetised rabbits to assess the irritancy of a wide range of products. It was selected as our next target, since it is a vividly painful procedure and has the potential to be replaced by non-whole-animal methods. Professor David Smyth, a leading member of the British Research Defence Society (RDS), a group which exists to counter attacks on animal experimentation, had suggested in print that the Draize eye test would be a good candidate for replacement by methods not using animals, both because it clearly caused suffering and because the development of an alternative should not present any major scientific problems (5). In addition, the Draize eye test could be targeted through the cosmetics industry, since we considered that using rabbits to test yet another mascara was both trivial and frivolous.

We went as far as we could within the system. For 18 months prior to our public campaign, we sought a meaningful dialogue leading to a collaborative approach. Dr Rack prepared a paper, outlining possible alternatives to the Draize test, which was presented to Revlon. It was only after Revlon refused to respond to our comments that we launched a public campaign, including a boycott of Revlon's products. With our one share of stock, we debated the issue with Revlon's President at stockholders' meetings. In April 1980, full-page newspaper advertisements were placed by the Millenium Guild featuring a white rabbit with the question, "How many rabbits does Revlon blind for beauty's sake?" A street theatre demonstration with live rabbits and a mime troupe simulating the Draize test generated enormous media coverage and public outrage. The campaign spread across the US, to Europe and Australia. By December 1980, productive discussions had begun, and within a few weeks Revlon committed $\$ 250,000$ a year to Rockefeller University's proposed research programme aimed at developing alternatives to the Draize test; this project is now in its fifth year. Our response was to publicise Revlon's pioneering role. This was our first use of a pattern of action which we believe has been useful in encouraging the drive towards alternatives. The Rockefeller initiative was rapidly followed by the setting up of the Johns Hopkins Center for Alternatives to Animal Testing (CAAT), which is supported by the cosmetics and other industries.

This was an enormous breakthrough-the beginning of a whole new field of in vitro toxicology in the US, which is now entering mainstream science, with its own literature, symposia, workshops and university centres.

In the wake of our Draize test public awareness campaign, the US Senate directed regulatory agencies to set aside time and money for the search for Draize test alternatives. This amendment's rapid passage was orchestrated by a congressional staff member, who is 
part of our think-tank. Meanwhile, US regulatory agencies curbed some of their most indefensible practices. Thus, substances known to be irritants, such as ammonia and oven cleaners, need not be re-tested in the eyes of rabbits, and the suggested number of rabbits needed per test for other products has been reduced by one-half to one-third, while requirements are being harmonised so that data can be shared.

At this time, the Soap \& Detergent Association (SDA) and Bausch \& Lomb are funding projects aimed at identifying the most promising alternatives to the Draize eye test, moving the process further towards validation and implementation.

\section{The Classic LD50 Test}

Once the Draize campaign gained momentum, we maintained the pressure and broadened our efforts by launching an international Coalition to Abolish the Classic LD50 Test. The LD50 test measures the dosage of chemical, per $\mathrm{kg}$ body weight, at which half of groups of 40 to 200 animals are killed, and is one of the most widely used of all the animal toxicity tests.

It wds again quite clear that this traditional method was not only inefficient and unreliable, involving pseudo-scientific precision, but that it had already come under attack from a small section of the scientific community, although without any apparent impact on attitudes or practices.

For a decade, Gerhard Zbinden, Director of the Swiss Institute for Toxicology, and pharmacology consultant for the World Health Organisation (WHO), had been saying that the classic LD50 test was obsolete, but there had been little response from the regulatory or scientific communities. This seemed like a perfect example of "cultural lag" in which the spread of information in the right directions would lead to action.

At this juncture, what we needed was the commitment of corporate scientific expertise towards replacement and reduction. Thus, we contacted the Pharmaceutical Manufacturers Association (PMA), as well as pharmaceutical corporations, urging them to come out publicly against the classic LD50.

Fortuitously, the grassroots Pennsylvania Animal Rights Coalition (PaARC) was preparing to demonstrate against Smith Kline \& French (SK \& F). In consultation with PaARC we suggested to SK \& F that they promote alternatives in-house and provide the leverage to get the PMA to challenge the LD50. In return, we would recommend that the protest be called off. The protest was called off, and on October 21 1982, the PMA, representing 149 research-based US pharmaceutical companies, asserted that "neither the toxicologist nor the clinical pharmacologist needs a precise LD50 value", that carefully controlled acute experiments produce more meaningful and relevant data with fewer animals, and that "regulatory requirements should accommodate this position" (6). The PMA's position was seconded by the Cosmetic, Toiletry \& Fragrance Association (CTFA) and by the SDA. Next, we contacted the National Society for Medical Research (NSMR), whereupon their Board of Directors unanimously approved a statement, which was adopted on December 14 1982, that the "routine use of the quantitative LD50 is not now scientifically justified..." and Dr David P. Rall, Director of the National Toxicology Program (NTP), wrote to us on March 31983 saying that the LD50 "is now an anachronism . . . I do not think the LD50 test provides much useful information about the health hazards to humans ... the NTP does not use the LD50." Then, in response to this growing consensus within the scientific, industrial and academic communities, the Food \& Drug Administration (FDA) met on November 9 1983, to review and clarify its policies. The expression of the consensus included ten cover stories in major US science/industry publications, a Johns Hopkins meeting on alternatives to the LD50 test (7), increasing public concern, and a letter from Congressman Bill Green (NY) signed by 73 other Members of the US Congress, asking federal agencies to eliminate the classic LD50 test. At the November meeting, the FDA and other US regulatory agencies asserted that a precise LD50 value is not required and that they would make this clear to industry $(8,9)$.

What were the consequences of these regulatory assertions? By mid-1985, surveys by our Coalition and by the CTFA indicated a reduction of approximately $75 \%$ over the past three years in the number of animals used in acute oral safety testing. This decrease was attributed 
to the use of "limit" and "range-finding" tests, as opposed to classic LD50 tests, as well as to an increased use of data banks.

The current promising situation is the result of many individuals working together over a long period of time. Together and cooperatively we helped build a consensus among all parties that these wastefil tests are not needed.

Unfortunately, even when there are no credible defenders, and the major battles have been won, the issue is not automatically dead. The classic LD50 has been significantly phased out, but there is still the inertia, that ever present human tendency to "do more of the same". For example, some companies are still using the LD50, presumably because of the problem of multi-national requirements. We have therefore encouraged a dialogue between, among others, Japanese industrial companies (as one of the largest and most bureaucratically cumbersome groups) and their regulators, and industrial and academic toxicologists.

\section{The Next Steps}

The LD50 and Draize tests are part of a larger issue: the use of an estimated 70 million laboratory animals in the US, alone, each year. The science community itself is becoming increasingly aware that you cannot order 1,000 rabbits or 10,000 rodents as casually as you order a case of light bulbs. One of the new emphases of the animal welfare and animal rights movements is that much unnecessary animal suffering is due to "creeping routinism", which needs to be countered with clear goals and the questioning of methods to generate more elegant, creative and conclusive scientific results. We all know that, in many areas of life, people have been able to do what many others thought could not be done. When a clear goal is maintained and the technology is available, somehow, there is often an answer.

Procter \& Gamble ( $P \& G$ ), in a policy paper entitled "Taking Animals Out of the Laboratory" (10), concluded that they are "committed to pursue actively the development, validation and adoption of new testing methods which serve to eliminate the need for the use of animals". It is P \& G's policy to publish their research in the scientific literature and "to work with the relevant regulatory agencies for their acceptance". P \& G has turned its thinking into action. Other companies have initiated similar efforts, including Bristol-Myers, Revlon and Avon.

Every user of laboratory animals must constantly ask: is this test necessary? Can this information be obtained without using animals, or with fewer animals and less painful methods? Hopefully, with such an ongoing review process, we can eliminate most animal suffiering while continuing our search for non-animal alternatives. We believe that the reassessment procedures will themselves generate further progress which will benefit both scientific research and enhance human health. For example, a potential benefit of Draize test alternatives research is that scientists may find chemicals that increase the rate of wound healing, leading to drugs that can speed healing in patients.

In our ongoing efforts to enlarge the sphere of our effectiveness, we expect to continue using the basic strategies outlined above. We shall remain, as in all our efforts to date, ever ready to greet the "adversary" as a needed collaborator. We shall continue to recognise the multiple and contradictory values that all participants bring to these dialogues and the degree to which clarification of issues must lead to a feeling of inevitable change that is powerful and sweeping. We feel that by proceeding in this way we are making animal rights a significant part of scientific thinking. A substantial and growing number of biological scientists already recognise that attention to the welfare of laboratory animals and the use of minimally intrusive techniques is not only compatible with scientific excellence, but can be expected to stimulate excellence.

In transcending the so-called conflict between scientific research and animal welfare, we arrive at a discipline whose moral, intellectual and imaginative quality is such that we can announce proudly, "Let knowledge grow that life may be enhanced". 


\section{References}

1. Rowan, A.N. (1984). Of Mice, Models, and Men: A Critical Evaluation of Animal Research, 323 pp. State University of New York Press: Albany, NY.

2. Singer, P. (1975). Animal Liberation, 302 pp. Random House: New York.

3. Spira, H. (1976). Animals suffer for science. In Our Town, pp. 26-27, Manhattan Media Corps: New York.

4. Wade, N. (1976). Animal rights: NIH cat sex study brings grief to New York Museum. Science, 194, 162-167.

5. Smyth, D.H. (1978). Alternatives to Animal Experiments, pp. 67-68, Scolar Press: London.

6. Schuker, J.A. (1982). Pharmaceutical Manufacturer's Association News Release, October 21, Washington DC.

7. Goldberg, A.M. (ed.) (1984). Acute Toxicity Testing: Alternative Approaches, $292 \mathrm{pp}$. Mary Ann Liebert Inc.: New York.

8. Agency Steering Committee on Animal Welfare Issues (1984). Final Report to the Commissioner, August 15, FDA Public Health Service: Rockville, MD.

9. Federal Register 19675 May 10, 1985, 50, 91.

10. Steinmann, M. (1983). Taking animals out of the laboratory. In Moonbeams, pp. 7-10, September, Procter \& Gamble: Cincinatti, $\mathrm{OH}$. 